ble describir ese estado de cosas por medio de proposiciones "que naturalmente pueden ser verdaderas o falsas", son correctos; pero ello no demuestra que tales proposiciones sean las que figuran en las inferencias jurídicas. Para percatarse de ello, basta examinar con cuidado los mismos ejemplos de Miró. La proposición: "todo aquel que en el Perú mata deliberadamente a otro quedará sometido a la acción del organismo estatal que lo sancionará con penitenciaria no menor de seis años", puede ser interpretada en dos formas muy distintas. Si la consideramos como juicio enunciativo, su sentido es que la persona que en el Perú mata deliberadamente a otro, está expuesta a sufrir la acción del organismo estatal que la sancionará de tal o cual manera. En tal hipótesis, el juicio estaría referido a un hecho futuro de realización incierta, y su sentido diferiría por completo del de la norma de derecho. Si considera. mos, por lo contrario, que la oración gramatical a ntes transcrita expresa -pese a su forma lingüística- una norma de derecho, su sentido sólo puede ser éste: si en el Perú una persona mata deliberadamente a otra (y se cumplen los demás requisitos que la ley señala), el juez deberá imponerle tal o cual pena. Ahora bien: de las dos proposiciones, la enunciativa y la normativa, sólo la segunda puede formar parte de un razonamiento jurídico $y$, por tanto, servir de base al fallo judicial. No así la otra, porque ni estatuye deberes jurídicos ni concede derechos subjetivos. De este modo el problema surge otra vez, ya que de la norma expresada por el artículo 150 del Código Penal del Perú no puede decirse - como lo reconoce el autor del libro que comentamos- que sea verdadera o falsa. Es más: de ella no puede siquiera afirmarse - de acuerdo con la tesis de Miró- que tenga el carácter de "proposición". De este atolladero sólo es posible salir cuando se advierte que al lado de los juicios predicativos que estudia la apofántica aristotélica hay otros normativos, y que los atributos que a éstos convienen no son los de verdad o falsedad, sino los de validez o invalidez.

La parte en que el autor hace el estudio de diversas teorías sobre la estructura lógica de la norma de derecho es muy interesante, y abunda en valiosas y agudas reflexiones críticas; pero su interés habría sido mucho mayor si Miró se hubiera referido en ella a las teorías que han abordado en forma más rigurosa y directa los mismos problemas que él examina en su obra. Queremos referirnos a las de Ulrich Klug y $\mathrm{H}$. von Wright, que el filósofo peruano cita y conoce a fondo.

\section{Eduardo García Máynez}

\section{Metafísica de la expresión, por Eduardo Nicol. Fondo de Cul- tura Económica, México, 1957.}

Lo menos que puede decirse de este libro es que es un libro bien construido y acabado, escrito en estilo vigoroso y límpido, fruto de una larga meditación filosófica, con inspección directa de las fuentes y pensamiento propio, en torno a la idea del hombre, definido en este libro como el ser de la expresión. "La expresión es el ser del hombre", había dicho ya Nicol desde La Vocación Humana, y ahora pretende darnos el cum. plimiento intuitivo de aquella intención. La antropología filosófica es así para el autor, desde su punto de vista, en todo convertible con la metafísica de la expresión.

Puesto que debe ser precisamente una metafísica, y no simplemente una física de la expresión o una fenomeno. logía de las formas simbólicas, etc., cree el autor necesario remontarse, en la primera parte de la obra, a la meta. física antigua con el objeto de ver si en aquella metafísica general no podría 
fundarse esta metafísica especial que persigue. Es éste un largo excurso por cierto en la economía de la obra, pero desde luego no carente de interés, y a tal punto que, aun si no pasáramo adelante, retendrán seguramente la atención del lector estas páginas en que Nicol somete a una severa aporética las cuestiones más cardinales de_la metafísica tradicional.

El resultado de este examen es para el autor francamente decepcionante. La "vieja ciencia del ser" presenta "la aparente posibilidad de incluir en ella los fenómenos expresivos" (pág. 28). "Para que sea posible una ciencia del ser, es necesario que el ser tenga atributos" (pág. 30); pero estos atributos, en opinión del autor, "resultarán forzosamente menos universales que el concepto mismo del ser" (pág. 31). Nicol se da bien cuenta de que la escolástica pretendió describir dichos atributos en la conocida teoría de los trascendentales del ente; pero esta teoría le parece ser una "nulidad epistemológica" y "la parte más estéril de toda la metafísica tradicional" (pág. 31). Tampoco ignora el autor, por otra parte, pues conoce bien su Aristóteles, que la metafísica podría ser también o principalmente teología (teología natural por supuesto), pero aun esto le parece imposible, en razón de que: "La metafísica, ciencia intermedia entre la física y la teología, trataría del ser, y no podría recurrir al concepto de Dios para aclarar el ser mismo, porque Dios es inaccesible al entendimiento humano pro statu isto" (pág. 37). En suma, pues, "parece ha. her llegado el momento de convencerse definitivamente de que no hay una ciencia del ser en cuanto tal" (pág. 39). La única metafísica posible es aquella que "pueda organizarse fenomenológicamente" (pág. 46), o sea, si glosamos con fidelidad el pensamiento del autor, aquella que no trasciende los fenómenos mismos. Por último, y en lo que hace directamente a la expresión, ésta tampoco recibió en la metafísica tradicional el tratamiento que demandaba como "carácter constitutivo de la estructura ontológica del hombre". La expresión, podría pensar cualquiera de momento, no sería otra que el logos mismo, dado por Aristóteles como carácter definitorio del viviente humano; pero Nicol se apresura_a_desvanecer_esta_equiparación porque: "El logos, que si era un carácter ontológico fue considerado como tal solamente en tanto que no era una expresión" (pág. 72).

¿Será entonces que deberemos contentarnos con una física de la expresión, - y tanto más cuanto que la expresión “está siempre circunscrita primariamente por un quién, por un aquí y un ahora, es decir, es un fenómeno que se presenta determinado desde luego por unos caracteres de singularidad? (pág. 79). Y en este supuesto, como perteneciente a todo en todo al mundo del devenir "¿no podrán, entonces, las ciencias llamadas del espíritu, que son ciencias del cambio también bastarse por sí solas para tratar de este fenómeno?" (pág. 126). El autor, sin embargo, es de opinión que no bastan, por cuanto que "el problema de primer plano no son las formas de expresión simbólica creadas por el hombre, sino la estructura ontológica del hombre como creador de esas formas"; y siendo así, el problema que se plantea es "directamente metafísico, sin dejar por ello de ser fenomenológico" (pág. 127).

Sobre esta base, pues, de la metafísica fenomenológica, la expresión le aparece al autor como "el primer dato fenoménico que nos ofrece el ser humano", como el antecedente de todos los demás, y en suma, "la clave para la comprensión de la forma de ser propia del hombre" (pág. 203). Y es así porque "su ser no está completo ni puede completamente conocerse, en la pura determinación óntica de su individualidad", ya que "la necesidad de ser con el otro no es sociológica, sino metafí- 
sica" (pág. 204). Pero más aún, y si la misma aprehensión del ser, de cualquier modo que sea, "implica ya el concurso de la palabra dialogada, y toda palabra es expresión", resultará entonces que la metafísica de la expresión será, ni más ni menos, la filosofia primera; y en efecto, Nicol le asigna resueltamente esta hegemonía en este pasaje transparente: "La teoría del hombre como ser de la expresión no ha de fundarse en una ontología previamente establecida, sino que, por el contrario, la metafísica de la expresión es la base originaria en que debe asentarse la ontología como investigación fenomenológica de la forma de ser de los entes" (pág. 210).

Este vasto programa es el que trata de explicitar el autor en la segunda mitad de su obra, cuyas partes tercera, cuarta y quinta llevan como epígrafes, respectivamente, "El que expresa", "Lo que expresa" y "Cómo expresa". El que expresa es, por supuesto, el hombre y sólo el hombre, único ente expresivo, y cuya única "constante ontológica" es la expresión. No es posible dar de él una definición por el logos (que, según el autor, perdió desde muy temprano en carácter expresivo) ni por existenciales o existenciarios, pues la angustia, por ejemplo, es ella misma una expresión, Y por más que en este momento histórico parezca ser la prevalente, mañana podrá serlo "la serenidad o la alegría" (pág. 220).

La comprobación de que "al ser humano lo reconocemos y distinguimos metafísicamente de inmediato por el hecho simple de que nos habla" (pág. 233), le permite al autor resolver, o desplazar mejor dicho, el falso problema de la intercomunicación humana que planteó la metafísica cartesiana, dado que el cuerpo está también implí. cito y coimplícito en la expresión; y le da pie asimismo para enfocar bajo este nuevo ángulo el problema de la verdad. En su concepto, "la verdad es dialógica, porque se formula como referencia real de los interlocutores a una realidad ca mún" (pág. 247). La conformidad co la realidad es en ella cosa secundari pues la verdad es "sobre todo una e: presión", y "la intencionalidad prim: ria es dialógica" (pág. 257), comun cativa; y la verdad, por ende, "es . modo de ser constitutivo del hombr por el cual se establece la vinculació existencial entre un hombre y otro hon bre" (pág. 260). La clásica adaequ tio rei et intellectus no puede en absi luto entenderse "como relación de la p: labra con la cosa", sino "como relació entre quien usa la palabra y aquel quien la palabra se dirige, cuando an bos la entienden para referirse a un realidad común" (pág. 263). Con esı sello eminentemente práctico y ético $d$ la verdad, nos explicamos que, para autor, la verdad de una proposició cualquiera no necesite verificarse $d$ otro modo que por el consenso de lc dialogantes: "Sólo el diálogo puede se la garantía suficiente de que lo captad intuitivamente no es una ilusión, sin una realidad efectiva. Por encima d esta garantía no se dispone de otra pero tampoco se requiere." "Nos enter demos: luego hay verdad" (pág. 291) "La evidencia del ser no reside en $]$ conciencia, sino en el logos" (pág. 290) en un logos que es esencialmente, com hemos visto, un diálogo.

Las necesidades de una metafísica d la expresión llevan al autor a continu: ción ("Lo que expresa") a "examina lo que haya de común en toda expri sión, independientemente de las dif, rencias de forma y contenido" (pá 298). Pues bien, "lo que expresa? hombre, primaria y fundamentalment es la forma común del ser: $\mathrm{El}$ hombr como ser de comunidad" (pág. 307) "La expresión constituye la comunida histórica, y es el hilo conductor por a cual puede actualizarse el pasado histc riográficamente" (pág. 311). Ahor bien, una hermenéutica del ser de l expresión es una hermenéutica del ser 
tido, categoría implicada en todo lo humano, y que no es "primariamente un concepto de lógica o de semántica, sino una categoría existencial y ontológica" (pág. 332).

En la última parte ("Cómo expresa") el autor pretende esbozar lo que llama él mismo una Crítica de la razón simbólica, a la cual lo llevan naturalmente sus lucubraciones precedentes,-desde-almomento que "en un sentido radical, toda expresión es simbólica" (pág. 352); afirmación que pretende justificar apartándose de la noción corriente de símbolo, el cual, como en la lengua griega, sería esta vez toda expresión cualquiera que, al ser entendida por la otra parte, efectúa la re-unión entre los actos intencionales de los interlocutores. No desconoce Nicol, antes por el contrario hace de ello buen acopio, la fecunda aportación que en este terreno representa la Filosofía de las formas simbólicas de Cassirer, pero estima, con todo, que "El principio de la Unidad del espíritu, frente a la diversidad de sus manifestaciones, no adquiere en Cassirer la fuerza de un principio de comunidad" (pág. 365), y que lo que importa más no es tanto mostrar la unidad entre las distintas formas simbólicas, sino su interdependencia e interconexión de sentido; lo cual hace el autor de manera por cierto brillante y sugestiva, merced al comercio cordial y comprensivo que Nicol ha mantenido siempre, sin mengua de su especialización profesional, con otros territorios de la cultura, como son las ciencias, el arte y la literatura. Esta interconexión de sentido se ofrece históricamente, en su opinión, de acuerdo con una estructura que tiene éstas por dimensiones: "la dimensión vertical, según la cual aparecen en concordancia todas las formas simbólicas de una misma situación, y la dimensión horizontal, en la que se revelan las concordancias de continuidad entre cada una y sus antecedentes" (pág. 373). La obra remata con la enunciación y comentario de los cinco principios de la relación simbólica; quintuple relación que mantiene el símbolo con su productor, con su intérprete, con su objeto intencional, con otros símbolos para formar con ellos un sistema con su propia unidad de sentido, y finalmente con su pasado histórico. Esta última relación da ocasión al autor para exponer sus puntos de vista sobre la historicidad de las formas simbólicas.

Mucho y muy valioso habrá quedado sin duda fuera de esta reseña; pero en ella no es posible otra cosa que describir con fidelidad, como creemos haberlo hecho, las directrices esenciales de la obra; y asimismo, por las propias razones, no es tampoco posible entrar ahora en un análisis crítico pormenorizado. Lo único que en general podríamos decir a este respecto, es que este libro tiene todos los méritos y todas las limitaciones que lleve consigo el empleo exclusivo del método fenomenológico; exclusividad inobjetable, por supuesto, cuando sólo se trata de hacer fenomenologia, pero no cuando se pretende hacer, con ello y sólo ello, metafísica. La fenomenología, en efecto, como lo reconoce el autor, no puede sino mostrar lo que "ha de estar ya latente en los fenómenos mismos" (pág. 303) y en este sentido es una obra prima este libro de Nicol; pero lo que, en cambio, es más que discutible, es que al mostrar también "el fundamento de todos los fenómenos, presente en cada uno" (pág. 303), quede con esto sólo convertida la fenomenologia en metafisica. Porque no es de ningún modo evidente que el fundamento de todo fenómeno haya de estar siempre y necesariamente dado en el fenómeno mismo, sino que bien pudieran remitir los fenómenos a algo transfenoménico, como lo creyó la antigua metafísica, y cuya existencia se imponga a la razón con no menor fuerza que el fenómeno, si es que verdaderamente queremos dar 
razón de los fenómenos y no simplemente limitarnos a describirlos. ¿ $\mathrm{O}$ es que está demostrado también que la inteligencia humana no puede ir más allá de esta operación descriptiva, neutral, $y$ apenas preparatoria de la obra que es con mucho la principal?

En fuerza de estos presupuestos, de esta clausura hermética en el método fenomenológico, nos explicamos la posición escéptica del autor en puntos tan vitales como algunos de los que antes hemos tocado. Partiendo, por ejemplo, de la comprobación para todos incues. tionable de que Dios no es un fenómeno (Deum esse non est per se notum, saltem quoad nos) el autor pasa inmediatamente a afirmar, como hemos visto, que Dios es inaccesible al entendimiento humano in statu viae, cuando para la teodicea cristiana, por el contrario el fenómeno visible remite, con necesidad impositiva, a lo transfenoménico invisible: Invisibilia Dei per ea quae facta sunt, intellecta, conspiciuntur... (Rom., $I, 21)$ y otro tanto, en su orden, en lo que atañe al problema de la verdad que el autor deja reducida, en fin de cuentas, al consenso social.

Por otra parte, estaría por averiguarse esto de que los griegos mismos hayan eviscerado al logos de su expresividad al punto que Nicol parece afirmarlo. En estos días acaba de publicarse en Río un importante ensayo: "O Logos heraclitico" de frei Damiáo Berge, quien dice querer contribuir en su trabajo al problema de la relación entre pensamiento y expresión ya que: "No hay pensamiento sin palabra, y es en ésta, según Heráclito, en que se expresa aquél." $\mathrm{Y}$ aun en Aristóteles mismo, recordemos no más cómo lo del viviente político es una definición del hombre tan cabal y precisa como la otra en función del logos; ahora bien, si el logos en la ciudad no es un logos expresivo, no sabríamos decir cuál pueda serlo. De modo, pues, que acaso estaría mejor no hacer tabla rasa del pasado, sino, más constructivamente, proseguir, ahondar y enriquecer, con todas las contribuciones fenomenológicas que se desee, aquellas intuiciones que por algo son aún hoy el fundamento y toda antropología filosófica.

A propósito de otro asunto, pero en este mismo Anuario, nos explicamos más largamente sobre la colaboración que debe haber, para bien de entrambas, entre fenomenología y metafísica, y sobre la imposibilidad de subsumir ésta en aquélla. Por ello no insistimos más en este punto, y apenas nos limitamos a ponderar cuán vastos horizontes podrían abrirse a una fenomenología de la expresión que a la postre desembocara en una auténtica metafísica del ser humano y del ser en general. El logos humano cobraría así verdaderamente todo su valor expresivo al arraigar en el Logos creador, porque "lo que debe expresar" (por algo este capítulo está ausente de la obra que comentamos) este logos nuestro es el orden de esencias y valores que en toda la jerarquía óntica ha impreso el Logos por antonomasia; y si prescindimos de estas vinculaciones ontológicas y axiológicas, no tendremos, en definitiva, sino un puro hablar por hablar. 0 por otra vía aún: si el hombre tiene realmente algo que expresar, no es porque se lo saque de sí mismo, sino porque todo lo que no es él, o sea el ente en general, es a su modo también expresable o expresivo; porque todo ente, verum et bonum, expresa, irradia de sí verdad y valor, y en la expresión humana deben recibirse, valorizarse, y aun comunicarse por ventura nueva refulgencia a estas irradia. ciones. ¿Cómo podremos prescindir, en una metafísica de la expresión, de éstas que parecen ser sus condiciones primarias de posibilidad y de valor?

Otra crítica cualquiera estaría en este momento fuera de lugar, y aun de la anterior hubiera prescindido si esta nota fuera tan sólo para cubrir el expediente, pero no cuando está de por medio 
un filósofo auténtico como Eduardo Nicol, que ama la verdad, que siempre ha dicho arrojadamente la que cree ser tal, $y$ ante quien, por ende, no puede uno limitarse a gestos perfunctorios de cortesía o de neutralidad benévola. Esto podrá estar bien en otro terreno, pero no entre quienes conviven hace años en una comunidad a la_par fraterna-y ligerante, en la cual -ahora más que nunca- la expresión dialogada de sus miembros debe ser entera y sin reservas.

\section{Antonio Gómez Robledo}

Ensayo sobre las virtudes intelectuales, por Antonio Gómez Robledo. Publicaciones de Diánoia, Fondo de Cultura Económica, México, 1957.

Después de su excelente traducción de la Etica Nicomaquea, publicada en la Bibliotheca Scriptorum Graecorum et Romanorum de la Universidad Nacional de México, Gómez Robledo nos ofrece ahora el fruto de sus estudios sobre las virtudes intelectuales en Aristóteles. Preciso es, ante todo, destacar la originalidad e importancia de esta investigación. Recorriendo las bibliografías filosóficas, nos percataremos del escaso número de monografías consagradas especialmente a este tema. El autor cita una (pág. 43) : la de Lienhard Eberlein (Die dianoëtischen Tugenden der Nikomachischen Ethik nach ihrem Sinn und ihrer Bedeutung), y el comentario de Greenwood al libro VI de la Etica $\mathrm{Ni}$ comaquea, publicado en Cambridge en 1906. A estas obras podríamos agregar otras dos: la de Kühn (De Ar. virtutibus intellectualibus, Berlin, 1860) y la más reciente de Raimbaud (Intr. à l'étude des Vertus intellectuelles, Coutances, 1942). Preciso es, pues, destacar también el que dentro de la producción filosófica en Hispanoamérica, ésta es una de las obras que pueden considerarse como excepcionales.

Excepcional no sólo por lo que toca a las reflexiones personales del autor, sino por su valor para la historiografía filosófica. Porque, de hecho, el libro que vamos a reseñar aquí requiere ser visto bajo este doble aspecto. Gómez Robledo-nos-adwierte- -eñ efecto, que "este comentario, si bien puede llamarse así, no lo es con la pureza metódica ni el ayuno riguroso de otros ingredientes no contenidos formalmente en el contexto mismo, con que suelen hacer estas cosas los scholars europeos, por ejemplo. Más bien se parecería a los antiguos comentarios escolásticos, en los cuales el texto era a menudo un pretexto para que cada cual pudiera libremente 'mover sus cuestiones', como decía Vitoria... Pues de la misma licencia he hecho uso largamente en este trabajo, sin cuidarme mucho de patrones europeos a que no tiene por qué ajustarse tan sumisamente un hispanoamericano, para el cual la filosofia, si no distinto contenido, tiene por lo menos sus formas propias de expresión" (págs. 12. 13). Un autor tiene siempre el derecho de escoger la forma de expresión que mejor se adapte a sus propósitos; pero no creemos que el hispanoamericano esté condicionado necesariamente, sea por causas psicológicas, hereditarias, "ontológicas" o las que se quiera, a escribir filosofía o historia de la filosofía de un modo determinado, esto es, a la "hispanoamericana". Por lo demás, hay que advertir que sólo nos ocuparemos del aspecto de este libro que más claramente compete a la historiografía filosófica, señalando aquellos puntos que, a nuestro juicio, necesitarian ampliarse o modificarse. Manera limitada de enfocarlo, pero no injusta; pues ahí reside una gran parte de su mérito.

El libro se inicia con un resumen de la teoría general aristotélica de la vir. tud. Una vez dada la definición formal de ésta, su autor nos presenta los ele. 